\title{
Effects of Varying Environmental Conditions on Biological Control of Fusarium Wilt of Tomato by Nonpathogenic Fusarium spp.
}

\author{
Robert P. Larkin and Deborah R. Fravel
}

First author: USDA-ARS, New England Plant, Soil, and Water Lab, Orono, ME 04469; and second author: USDA-ARS, Vegetable Laboratory, Beltsville, MD 20705.

Accepted for publication 16 July 2002.

\begin{abstract}
Larkin, R. P., and Fravel, D. R. 2002. Effects of varying environmental conditions on biological control of Fusarium wilt of tomato by nonpathogenic Fusarium spp. Phytopathology 92:1160-1166.

The influence of varying environmental and cropping conditions including temperature, light, soil type, pathogen isolate and race, and cultivar of tomato on biological control of Fusarium wilt of tomato by isolates of nonpathogenic Fusarium oxysporum (CS-20 and CS-24) and F. solani (CS-1) was evaluated in greenhouse and growth chamber experiments. Liquid spore suspensions $\left(10^{6} / \mathrm{ml}\right)$ of the biocontrol isolates were applied to soilless potting mix at the time of tomato seeding, and the seedlings were transplanted into pathogen-infested field soil 2 weeks later. Temperature regimes ranging from 22 to $32^{\circ} \mathrm{C}$ significantly affected disease development and plant physiological parameters. Biocontrol isolate CS-20 significantly reduced disease at all temperature regimes tested, yielding reductions of disease incidence of 59 to $100 \%$ relative to pathogen control treatments. Isolates CS-24 and CS-1 reduced disease incidence in the greenhouse and at high temperatures, but were less effective at the optimum temperature for disease development $\left(27^{\circ} \mathrm{C}\right)$. Growing plants under shade
\end{abstract}

ABSTRACT

Biological control of Fusarium wilt diseases, caused by pathogenic formae speciales of Fusarium oxysporum, through nonpathogenic soil isolates of Fusarium spp. has shown potential as an alternative disease management strategy $(3,8)$. Selected isolates of avirulent or nonpathogenic $F$. oxysporum or $F$. solani have successfully reduced the incidence of Fusarium wilt in numerous crops in greenhouse and field trials $(1,2,8,15,16,20,22$, 23,25,30).

Previously, we demonstrated the efficacy of several strains of nonpathogenic Fusarium spp. isolated from a wilt-suppressive soil in controlling Fusarium wilt of tomato and other vegetable crops in greenhouse tests (20). Selected isolates were equally effective at reducing Fusarium wilt of tomato, watermelon, and muskmelon in repeated tests, with reductions in disease incidence of 60 to $80 \%$ relative to the pathogen-infested controls (20). We also demonstrated that the mechanism of action of biocontrol by two of these isolates (CS-1 and CS-20) involved induced systemic resistance, and that these isolates effectively reduced disease incidence at low biocontrol inoculum densities and high pathogen densities (21). These results indicated a high potential for development of these isolates as biocontrol agents.

However, before biological control by these or any other agents can be practically implemented, it is essential to determine how

Corresponding author: R. P. Larkin; E-mail address: larkin@maine.edu

Publication no. P-2002-0909-02R

This article is in the public domain and not copyrightable. It may be freely reprinted with customary crediting of the source. The American Phytopathological Society, 2002.
(50\% of full light) versus full light affected some plant growth parameters, but did not affect the efficacy of biocontrol of any of the three biocontrol isolates. Isolate CS-20 effectively reduced disease incidence (56 to $79 \%$ reduction) in four different field soils varying in texture (sandy to clayey) and organic matter content (0 to $3.2 \%)$. Isolate CS- 1 reduced disease in the sandy and loamy soils (49 to $66 \%$ reduction), but was not effective in a heavy clay soil. Both CS-1 and CS-20 were equally effective against all three races of the pathogen, as well as multiple isolates of each race (48 to $66 \%$ reduction in disease incidence). Both isolates, CS-1 and CS-20, were equally effective in reducing disease incidence (66 to $80 \%$ reduction) by pathogenic races 1,2 , and 3 on eight different tomato cultivars containing varying levels of inherent resistance to Fusarium wilt (susceptible, resistant to race 1, or resistant to races 1 and 2). These results demonstrate that both these Fusarium isolates, and particularly CS20, can effectively reduce Fusarium wilt disease of tomato under a variety of environmental conditions and have potential for further development.

Additional keywords: F. oxysporum f. sp. lycopersici, induced systemic resistence, wilt suppression.

biological control may be affected by changing environmental conditions. Overall, it is important to learn as much as possible regarding the ecology of these biocontrol organisms and their interactions with the pathogen, host plant, soil and rhizosphere microbial communities, and their surrounding environments $(7,13$, 26). Many attempts at biological control have resulted in inconsistent or unsatisfactory disease control under varying environmental conditions and locations. This inconsistency may be related, at least in part, to a general lack of understanding of how these biocontrol systems work and under what conditions they may or may not be expected to function. This has resulted in the introduction of biocontrol organisms into environments in which they are ecologically unsuited (10). Any individual biocontrol organism can only be expected to perform within a limited set of physical, biological, and environmental conditions. Yet, in most cases, these conditions are not adequately defined.

Basic environmental conditions, such as temperature, moisture, sunlight, and soil physical and chemical characteristics, can greatly affect the physiology of the host plant and subsequent disease development, as well as alter the interactions among plant, pathogen, and biocontrol agent in various ways. This is in addition to potential direct effects on the pathogen and biocontrol organisms and other soil microbes, and all of these effects may influence efficacy of biological control. Other conditions related to the specific pathosystem involved, such as the occurrence of different pathogenic races and variability in disease resistance and susceptibility among host cultivars, also affect the disease response and may influence biological control.

There are three known races of $F$. oxysporum f. sp. lycopersici, the causal agent of Fusarium wilt of tomato $(4,9,12,31)$. Tomato 
cultivars with inherent genetic resistance to races 1 and 2 are available and widely used. However, very few cultivars with resistance to race 3 exist, and none are commercially accepted and used. This race is currently causing substantial losses in many tomato-growing areas $(6,17,27)$. For biocontrol to be effective, it must control all three races of the pathogen, as well as be capable of controlling disease on many different tomato cultivars with varying levels of disease susceptibility and resistance. This race and cultivar effect may be particularly important to determine for biocontrol agents such as CS-1 and CS-20 because induced resistance has been determined to be involved in their biocontrol interaction. Consequently, response to these biocontrol isolates and the capability for induced resistance may vary greatly among cultivars.

The objective of this research was to evaluate the effects of several different environmental conditions including temperature, light, soil type, pathogen race, and tomato cultivar on the efficacy of biological control of Fusarium wilt of tomato by selected nonpathogenic isolates of Fusarium spp. A preliminary report of portions of this work has been published (19).

\section{MATERIALS AND METHODS}

Fungal isolates and inoculum production. Antagonistic and pathogenic isolates of Fusarium spp. used in this study are listed in Table 1. Biocontrol isolates CS-1, CS-20, and CS-24 were isolated from watermelon plants grown in a wilt-suppressive soil in Florida (20,21). Isolates of $F$. oxysporum $\mathrm{f}$. sp. lycopersici of all three known pathogenic races were used in tests to determine the effect of pathogenic race on biocontrol activity. In all other tests, race 1 isolate IA-7 was used. Stock cultures of all Fusarium strains were stored on dried toothpicks, filter paper, or in soil. Inoculum was produced in an aqueous suspension of $1 \%$ (wt/vol) ground soybean hull fiber (Dietfiber soy fiber, Lauhoff Grain Co., Danville, IL) (14). Flasks containing $100 \mathrm{ml}$ of the autoclaved fiber suspension were inoculated with agar blocks from 7-day-old potato dextrose agar (PDA) culture plates. Liquid cultures were grown for 10 to 14 days on a rotary shaker at $135 \mathrm{rpm}$ at $25^{\circ} \mathrm{C}$, blended, and propagule counts determined with a hemacytometer. Inoculum consisted of a mixture of conidia and chlamydospores, and inoculum concentration was adjusted to $10^{6}$ propagules per $\mathrm{ml}$ prior to soil infestation for all experiments.

Disease assays. For all disease assays, tomato seeds of the cv. Bonny Best (Totally Tomatoes, Augusta, GA) were planted in soilless potting mix (Redi-Earth, Scotts-Sierra Inc., Marysville, $\mathrm{OH}$ ) and grown in seedling plug trays (plug size $3.4 \times 3.4 \times 5 \mathrm{~cm}$, 98 plugs per tray). The potting mix was either infested with one of the biocontrol isolates or left untreated. Five milliliters of a liquid culture suspension of $10^{6}$ propagules per $\mathrm{ml}$ of the biocontrol isolate was added to each plug cell at the time of planting. Five tomato seeds were planted in each cell of the plug tray and maintained in the greenhouse. After 2 weeks, plugs containing the tomato plants were transplanted into 10 -cm-diameter pots contain- ing nonsterile field soil (Galestown gravelly loamy sand) infested with the Fusarium wilt pathogen. Pathogen inoculum consisted of F. oxysporum f. sp. lycopersici grown in a liquid soy culture as described above. Final pathogen inoculum density in field soil was $10^{4}$ propagules per $\mathrm{g}$ of soil.

Each treatment consisted of five replicate pots of five plants per pot. Disease was monitored for 4 to 6 weeks (depending on variation in the time needed for reliable symptom expression) and assayed as the total percentage of seedlings showing any symptoms of Fusarium wilt (yellowing, dropping of leaves, vascular discoloration, etc.). Stem sections of wilted seedlings were surface-disinfested in $0.5 \%$ sodium hypochlorite and plated on Komada's Fusarium-selective medium (KM) (18) to confirm the presence of the wilt pathogen. In several experiments, stems from all seedlings were surface-sterilized and plated on KM at the conclusion of the test to determine all seedlings that were systemically infected by the pathogen and to compare these findings with wilt incidence determined by symptom expression. In all cases, systemic infection determined by plating was virtually identical to wilt incidence determined by symptom expression indicating that the assay effectively determined systemic infection by the pathogen. Thus, stem plating of all plants was conducted in subsequent experiments only when symptom expression was not conclusive.

This assay was designed to represent a transplant operation into infested field soil. It encompasses the critical period for systemic infection of tomatoes (first 2 to 4 weeks after transplanting), establishes a disease-conducive environment enabling symptom expression to be observed in a short time period (4 to 6 weeks), provides a reliable estimate of disease incidence (based on a total of 25 plants per treatment), and effectively assesses systemic infection, which is the critical determinant for symptom development in more mature plants. In preliminary experiments, allowing plants to grow for longer periods, in bigger pots, or using greater numbers of plants did not affect or improve assessment of disease incidence or systemic infection.

Effect of temperature and lighting conditions. Three different temperature regimes representing cool, warm, and hot conditions were established in environmental growth chambers to evaluate the influence of temperature on biocontrol efficacy. The growth chambers maintained daytime (14-h day) temperatures of 22,27 , and $32^{\circ} \mathrm{C}$ for the cool, warm, and hot regimes, respectively, and nightime temperatures (10-h night) of 16, 22, and $26^{\circ} \mathrm{C}$. Two different lighting conditions were also imposed within the growth chambers, representing full light (100\%) and partial shade (50\% of full light) conditions. Illumination was provided by fluorescent lights in the growth chambers. Shading was accomplished by covering the light banks in one-half of each growth chamber with brown paper. Light intensity was measured at $\approx 500$ and $\approx 250 \mu \mathrm{mol} / \mathrm{m}^{2} / \mathrm{s}$ by a quantum light meter (Spectrum Technologies, Plainfield, IL) for full light and partial shade treatments, respectively. In addition, a corresponding test was also conducted under normal greenhouse conditions to compare the growth chamber results with our normal greenhouse conditions. In

TABLE 1. Description, characteristics, and sources of Fusarium spp. biocontrol and pathogen isolates used in this study

\begin{tabular}{|c|c|c|c|}
\hline Isolate & Organism & Characteristics & Source \\
\hline CS-1 & Fusarium solani & Nonpathogen-biocontrol agent & $\mathrm{FWS}^{\mathrm{x}}, \mathrm{FL}(21)$ \\
\hline CS-20 & F. oxysporum & Nonpathogen-biocontrol agent & FWS, FL (21) \\
\hline $\mathrm{CS}-24$ & F. oxysporum & Nonpathogen-biocontrol agent & FWS, FL (21) \\
\hline IA-7 & F. oxysporum f. sp. lycopersici & Tomato pathogen - race 1 & R. Schneider ${ }^{y}$ \\
\hline HMS-3 & F. oxysporum f. sp. lycopersici & Tomato pathogen - race 1 & R. Schneider ${ }^{y}$ \\
\hline NK-4 & F. oxysporum f. sp. lycopersici & Tomato pathogen - race 2 & R. Schneider ${ }^{y}$ \\
\hline O-1078 & F. oxysporum f. sp. lycopersici & Tomato pathogen - race 2 & R. Schneider ${ }^{y}$ \\
\hline F20 & F. oxysporum f. sp. lycopersici & Tomato pathogen - race 3 & D. Chellemi ${ }^{\mathrm{z}}$ \\
\hline F28 & F. oxysporum f. sp. lycopersici & Tomato pathogen - race 3 & D. Chellemi ${ }^{\mathrm{z}}$ \\
\hline
\end{tabular}

${ }^{\mathrm{x}} \mathrm{FWS}=$ Fusarium wilt-suppressive soil

y Louisiana State University, Baton Rouge.

${ }^{\mathrm{z}}$ USDA-ARS, Ft. Pierce, FL. 
the greenhouse, temperature was controlled to remain between 22 and $28^{\circ} \mathrm{C}$. Greenhouse trials also included full light and shade treatments with brown paper used to shade the direct light sources as in the growth chambers. Biocontrol isolates CS-1, CS-20, and CS-24 were used along with positive and negative pathogen control treatments. The experiment was conducted twice. To assess potential differences in plant physiological responses due to temperature and light treatments, plant height and fresh shoot weight were measured for plants in each pot at 5 weeks after transplanting. Disease assays were conducted as described previously.

Effect of soil type. Four soils representing different soil textures and properties available in the Beltsville area were used to evaluate the influence of soil characteristics on biocontrol efficacy. The four soils used were a Galestown gravelly loamy sand (GLS), a Rumford loamy sand (RLS), a Hatboro sandy loam (HSL), and a heavy clay subsoil (RC). Some of the physical properties of these soils, which vary primarily in texture and organic matter content are listed in Table 2. All soils were collected from sites on the Beltsville Agricultural Research Center, passed through a $0.5-\mathrm{cm}$ pore-size sieve and stored for up to 3 months before use. Biocontrol isolates CS-20 and CS-1 were compared with controls not treated with the biocontrol isolates and either treated or not treated with the pathogen. All other experiments used the GLS soil to represent the standard soil for this area.

Effect of pathogen isolate and race. Two separate isolates of each of the three pathogenic races of F. oxysporum f. sp. lycopersici were used to evaluate the influence of different pathogen isolates and races on biocontrol efficacy (Table 1). Biocontrol isolates CS-1 and CS-20 and an untreated control treatment were tested in conjunction with separate treatments of each pathogen isolate. Disease assays were conducted as described previously.

Effect of tomato cultivar (genetic resistance). Eight different tomato cultivars with varying levels of inherent genetic resistance to the Fusarium wilt pathogen were used to evaluate the influence of different tomato cultivars on biocontrol efficacy. The eight cultivars chosen represented tomatoes with no resistance to Fusarium wilt ('Bonny Best'), partial (multigenic) resistance to race 1 ('Marglobe' and 'Rutgers'), full (monogenic) resistance to race 1 ('Better Boy' and 'Miracle Sweet'), and full resistance to both races 1 and 2 ('Early Girl', 'Celebrity', and 'Big Beef') (Totally Tomatoes, Athens, GA). At the time these tests were conducted there were no resistant cultivars to race 3 available. Biocontrol isolates CS-1 and CS-20 and a nontreated control were tested on each cultivar and exposed to F. oxysporum f. sp. lycopersici pathogenic isolates HMS-3 (race 1), NK-4 (race 2), and F20 (race 3).

Statistical analyses. Statistical analyses for data from all assays were conducted using the general linear models procedures of the Statistical Analysis Systems version 6.10 (SAS Institute, Inc., Cary, NC). Experiments were analyzed using standard analysis of variance (ANOVA) with factorial treatment structure and interactions. Significance was evaluated at $P<0.05$ for all tests. Mean separation was accomplished using Fisher's protected least significant difference test. All data expressed as percentages were arcsine-transformed $\left(\sin ^{-1} \sqrt{x}\right)$ before analysis. In studies done over time, repeated measures analyses were conducted. Quantitative variables were assessed using orthogonal polynomial contrasts to determine significant trends. Experiments consisted of five replicate pots of five seedlings per pot for each treatment combination. All experiments were conducted twice. Combined data from repeated experiments were analyzed with experiment as a factor to determine any effects or interactions due to experiment. In most cases, results were similar between repeated trials.

\section{RESULTS}

Effect of temperature and lighting conditions. Overall analyses determined that temperature, light, and biocontrol isolate significantly affected Fusarium wilt development with significant interactions between temperature and light and temperature and isolate (Table 3). These interactions indicate differing disease responses to light and biocontrol isolate at different temperature regimes.

When separated by temperature regime, differences in disease development among treatments were more apparent (Fig. 1). In the pathogen control treatment disease incidence was low $(7.8 \%)$ at cool temperatures $\left(22^{\circ} \mathrm{C}\right)$, severe $(77$ to $82.5 \%)$ at warm temperatures $\left(27^{\circ} \mathrm{C}\right.$ growth chamber and greenhouse conditions), and moderate $(45 \%)$ under the high temperature $\left(32^{\circ} \mathrm{C}\right)$ regime. Biocontrol isolate CS-20 significantly reduced disease incidence relative to the pathogen control treatment under all temperature regimes with disease incidences from 0 to $34 \%$, representing reductions in disease incidence from 59 to $100 \%$ across the different temperature regimes. Biocontrol isolates CS-24 and CS-1 significantly reduced disease incidence under greenhouse conditions and at the high temperature regime, representing 56 to $70 \%$ reductions in disease. These isolates were less effective at $27^{\circ} \mathrm{C}$ with only CS-1 significantly reducing disease.

Of the other plant growth indicators measured, plant height was significantly affected by biocontrol isolate with significant temperature by light and temperature by isolate interactions. Fresh shoot weight was significantly affected by all factors and interactions (Table 3). Plant height was significantly greater in CS-20treated plants $(20.9 \mathrm{~cm})$ than in the pathogen controls $(17.4$ to $18.8 \mathrm{~cm})$ at 22 and $27^{\circ} \mathrm{C}$ temperatures and significantly greater for all three biocontrol isolates (19.3 to $20.8 \mathrm{~cm}$ compared to $16.9 \mathrm{~cm}$ ) under greenhouse conditions. There was no difference in plant height among biocontrol isolates at the $32^{\circ} \mathrm{C}$ temperature regime (data not shown). Shoot fresh weight averaged significantly higher for plants treated with CS-1 and CS-20 at all three growth chamber temperature regimes and under greenhouse conditions, averaging 12.8 to $15.7 \mathrm{~g}$ per pot compared to 7.8 to $12.6 \mathrm{~g}$ per pot for the pathogen-treated controls.

Lighting conditions, of either high or low intensity, representing full sunlight and partial shade significantly affected disease incidence only under greenhouse conditions with significantly lower disease incidence observed in the shade than in full light (Fig. 2A). Lighting conditions also affected fresh weight under all temperature regimes with significantly lower plant biomass in shade than full light (Fig. 2B). Plants grown under shade conditions were more etiolated and spindly. However, plant height was only affected by lighting conditions at the $27^{\circ} \mathrm{C}$ temperature regime with significantly taller plants under full light conditions (Fig. 2C). Despite these effects of lighting conditions on disease de-

TABLE 2. Physical characteristics of the four soils used in evaluating the influence of soil type on biocontrol efficacy

\begin{tabular}{|c|c|c|c|c|c|c|c|}
\hline \multirow[b]{2}{*}{ Soil series/name } & \multirow[b]{2}{*}{ Designation } & \multirow[b]{2}{*}{$\mathrm{pH}$} & \multicolumn{5}{|c|}{ Texture $(\%)$} \\
\hline & & & Sand & Silt & Clay & $\mathrm{OM}^{\mathrm{y}}$ & $\mathrm{CEC}^{\mathrm{z}}$ \\
\hline Galestown gravelly loamy sand & GLS & 5.8 & 77.8 & 12.6 & 9.6 & 0.6 & 4.0 \\
\hline Rumford loamy sand & RLS & 6.0 & 76.8 & 8.1 & 15.1 & 1.0 & 4.6 \\
\hline Red clay subsoil & $\mathrm{RC}$ & 4.4 & 17.7 & 40.1 & 42.2 & 0.0 & 2.4 \\
\hline
\end{tabular}

y $\mathrm{OM}=$ Organic matter content (\% of dry weight).

${ }^{\mathrm{z}} \mathrm{CEC}=$ Cation exchange capacity $(\mathrm{me} / 100 \mathrm{~g})$. 
velopment and plant growth, there was no significant interaction between lighting condition and biocontrol isolate, indicating that effects of lighting were consistent across all biocontrol isolate treatments. Thus, there was no effect of lighting on disease reduction by the Fusarium isolates, with all three reducing disease equally well in the shade as in full light (Fig. 3).

Effect of soil type. Isolate CS-20 significantly reduced disease incidence in all four soil types tested including two loamy sands with low organic matter (GLS, RLS), a sandy loam with higher organic matter (HSL), and a heavy clay soil (RC), providing disease reductions of 56 to $79 \%$ relative to the pathogen control (Fig. 4). Isolate CS-1 significantly reduced the incidence of disease in

TABLE 3. Analysis of variance table evaluating the effects of temperature, lighting conditions, and biocontrol isolate treatments and their interactions on incidence of Fusarium wilt disease, plant height, and shoot fresh weight in tomato plants in greenhouse and growth chamber experiments

\begin{tabular}{lcccc}
\hline & & \multicolumn{3}{c}{$P>F^{\mathrm{x}}$} \\
\cline { 3 - 5 } Source $^{y}$ & $\mathrm{df}^{\mathrm{z}}$ & $\begin{array}{c}\text { Disease } \\
\text { incidence }\end{array}$ & $\begin{array}{c}\text { Shoot fresh } \\
\text { weight }\end{array}$ & $\begin{array}{c}\text { Plant } \\
\text { height }\end{array}$ \\
\hline Temperature & 3 & $0.0001^{* *}$ & $0.0001^{* *}$ & 0.5234 \\
Light & 1 & $0.0146^{*}$ & $0.0001^{* *}$ & 0.4594 \\
Temperature $\times$ light & 3 & $0.0006^{* *}$ & $0.0001^{* *}$ & $0.0436^{*}$ \\
Biocontrol isolate & 3 & $0.0001^{* *}$ & $0.0001^{* *}$ & $0.0002^{* *}$ \\
Temperature $\times$ isolate & 9 & $0.0341^{*}$ & $0.0004^{* *}$ & $0.0376^{*}$ \\
Light $\times$ isolate & 3 & 0.8980 & $0.0065^{* *}$ & 0.8390 \\
Temperature $\times$ light $\times$ isolate & 9 & 0.6231 & $0.0481^{*}$ & 0.6286 \\
\hline
\end{tabular}

${ }^{\mathrm{x}}$ Probability of a greater $F$ (level of significance) shown for each parameter measured. Probabilities of less than 0.05 and 0.01 are followed by single and double asterisks, respectively.

y Source of variation. Temperature regimes tested included cool $\left(22^{\circ} \mathrm{C}\right)$, warm $\left(27^{\circ} \mathrm{C}\right)$, and hot $\left(32^{\circ} \mathrm{C}\right)$ growth chamber conditions as well as normal greenhouse conditions $\left(22\right.$ to $\left.28^{\circ} \mathrm{C}\right)$ treatments. Lighting conditions consisted of full light or partial shade ( $50 \%$ of full light) treatments. Biocontrol isolate treatments included nonpathogenic $F$. oxysporum isolates CS-20 and $\mathrm{CS}-24$, and $F$. solani isolate CS-1, in addition to a pathogen-only treated control.

${ }^{\mathrm{z}}$ Degrees of freedom. Total $\mathrm{df}=158$ and error $\mathrm{df}=127$.

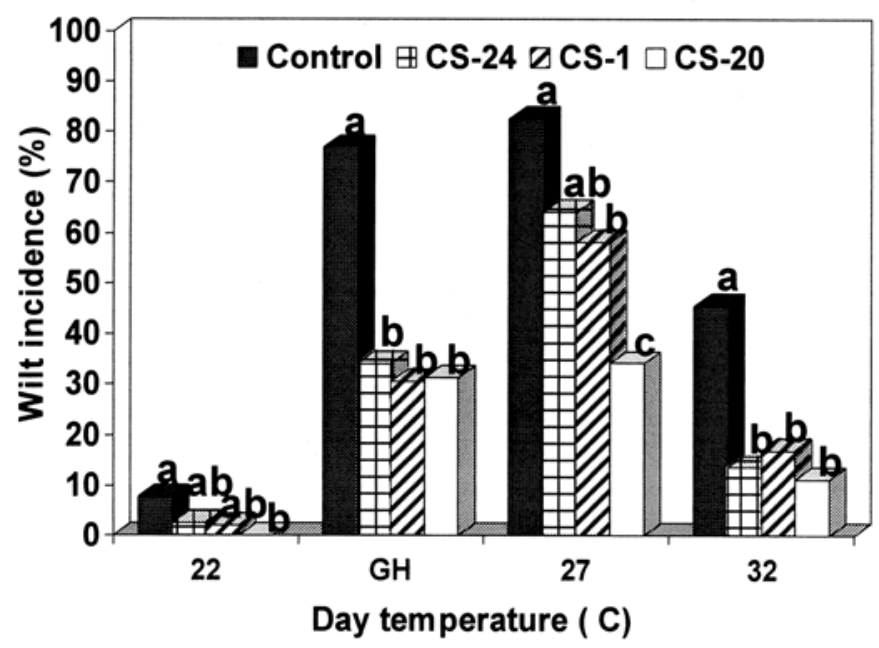

Fig. 1. Development of Fusarium wilt in tomato seedlings as affected by temperature regime and treatment with biocontrol isolates. Bars topped by the same letter within each temperature regime are not significantly different according to Fisher's protected least significant difference test at $P=0.05$. Data represent combined results of two experiments. Temperature regimes consisted of day $(14 \mathrm{~h})$ and night $(10 \mathrm{~h})$ temperatures of 22 and $16^{\circ} \mathrm{C}, 27$ and $22^{\circ} \mathrm{C}$, and 32 and $26^{\circ} \mathrm{C}$ for the three growth chamber treatments, and greenhouse $(\mathrm{GH})$ temperature conditions of 20 to $28^{\circ} \mathrm{C}$. Biocontrol isolates (CS-1, CS-20, CS-24, or nontreated control) were applied at seeding (final concentration at $10^{4} \mathrm{CFU} / \mathrm{g}$ of soil). All seedlings were transplanted into pathogen-infested field soil (pathogen concentration at $10^{4} \mathrm{CFU} / \mathrm{g}$ of soil) and wilt incidence determined 5 weeks later. all but the clay soil, reducing disease incidence by 49 to $66 \%$ and providing comparable disease reductions as isolate CS-20. Comparison of disease development in the pathogen control treatments for the four soils also indicated some variability in the relative conduciveness to Fusarium wilt disease among the soils. The sandy loam (HSL) soil resulted in significantly lower disease incidence than the two loamy sand soils (GLS and RLS), whereas disease incidence in the clay soil was in between that of the two other soil types, but was not significantly different from either (data not shown).

Effect of pathogen isolate and race. There was no significant difference in disease incidence between the two individual pathogen isolates within each race so data from both isolates for each pathogenic race were combined for all comparisons. All three races caused substantial disease in pathogen-treated control plants. Pathogen race had no effect on efficacy of biocontrol by either CS-1 or CS-20. Both isolates significantly reduced disease incidence equally well across all three pathogenic races with disease reductions of 56 to $66 \%$ and 48 to $61 \%$ for CS-20 and CS- 1 , respectively, relative to the pathogen controls (Fig. 5).
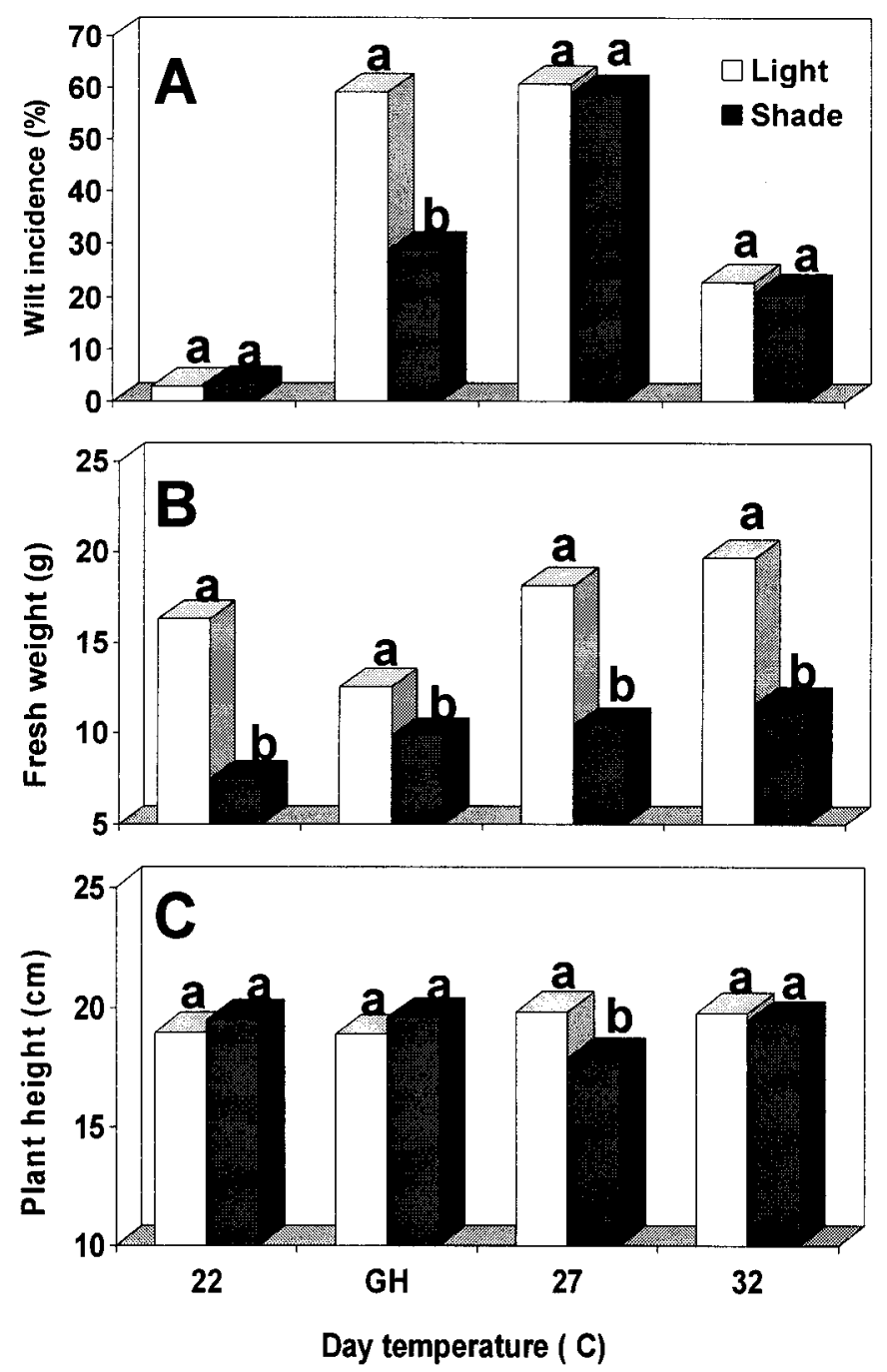

Fig. 2. Effects of lighting conditions and temperature regimes on $\mathbf{A}$, development of Fusarium wilt disease, $\mathbf{B}$, plant fresh weight, and $\mathbf{C}$, plant height in 5-week-old tomato seedlings. Bars topped by the same letter within each temperature regime are not significantly different according to Fisher's protected least significant difference test at $P=0.05$. Lighting conditions represent full light and $50 \%$ full light (shade). Temperature regimes consisted of day $(14 \mathrm{~h})$ and night $(10 \mathrm{~h})$ temperatures of 22 and $16^{\circ} \mathrm{C}, 27$ and $22^{\circ} \mathrm{C}$, and 32 and $26^{\circ} \mathrm{C}$ for the three growth chamber treatments and greenhouse $(\mathrm{GH})$ temperature conditions of 20 to $28^{\circ} \mathrm{C}$. 
Effect of tomato cultivar and disease resistance. Race 1 of the Fusarium wilt pathogen only caused substantial disease on one cultivar, the completely susceptible 'Bonny Best'. As in previous tests with race 1 , treatment with biocontrol isolates CS-1 and CS20 resulted in significant reductions in disease with disease incidence averaging $71.6 \%$ in the pathogen controls versus 35.1 and $24.0 \%$ in CS-1- and CS-20-treated plants, respectively (least significant difference $[\mathrm{LSD}]=22.3$ ). 'Marglobe' and 'Rutgers', which have partial multigenic resistance to race 1 , showed some plants with mild wilt symptoms in the pathogen control treatments, but these always represented less than 10 to $15 \%$ of plants

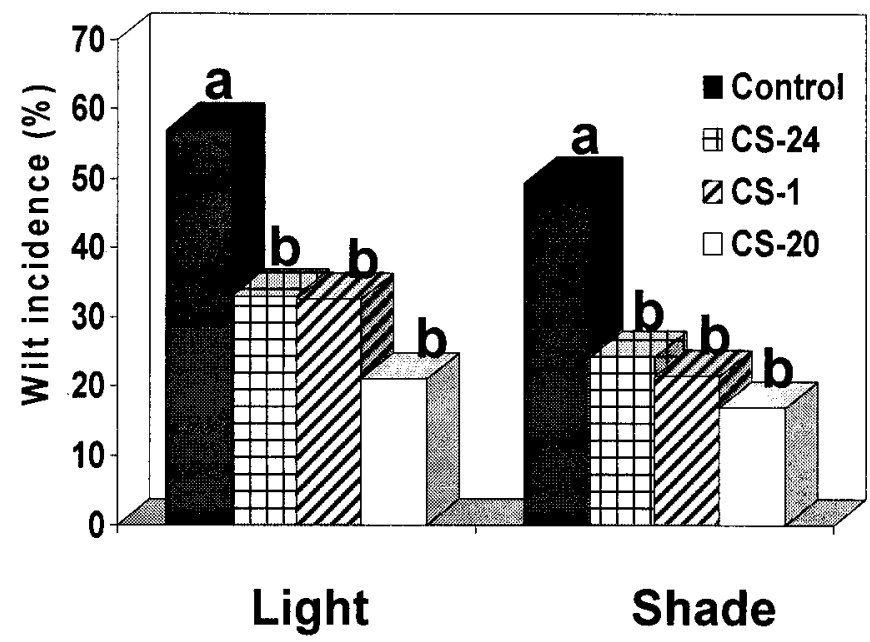

Fig. 3. Development of Fusarium wilt on tomato seedlings as affected by lighting conditions and biocontrol isolate treatments. Lighting conditions represent full light and 50\% full light (shade). Bars topped by the same letter within each lighting condition are not significantly different according to Fisher's protected least significant difference test at $P=0.05$. Biocontrol isolates (CS-1, CS-20, CS-24, or nontreated control) were applied at seeding (final concentration at $10^{4} \mathrm{CFU} / \mathrm{g}$ of soil). All seedlings were transplanted into pathogen-infested field soil (pathogen concentration at $10^{4} \mathrm{CFU} / \mathrm{g}$ of soil) and wilt incidence determined 5 weeks later.

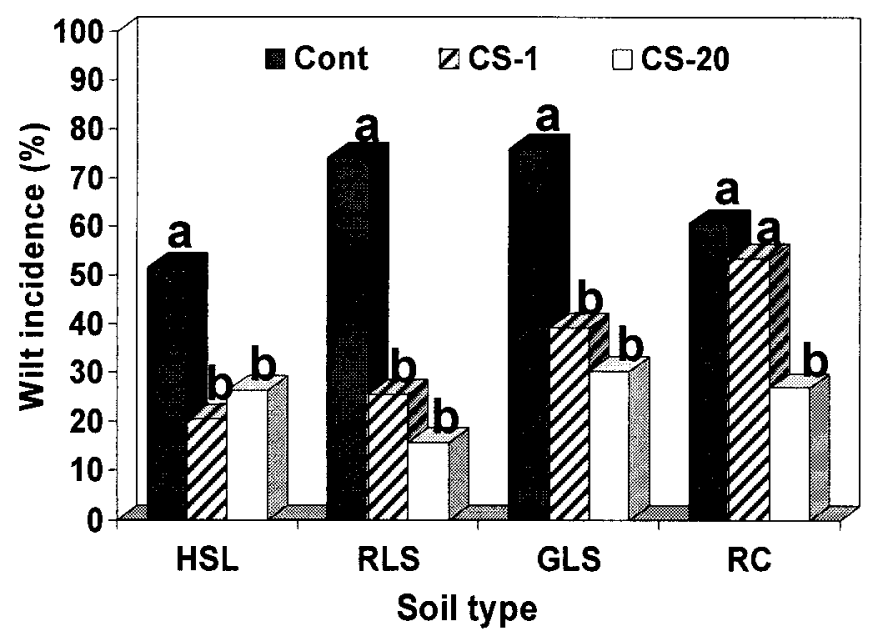

Fig. 4. Development of Fusarium wilt of tomato seedlings as affected by soil type and treatment with biocontrol isolates. Bars topped by the same letter within each soil type are not significantly different according to Fisher's protected least significant difference test at $P=0.05$. Data represent combined results of two experiments. Soil types consisted of Hatboro sandy loam (HSL), Rumford loamy sand (RLS), Galestown loamy sand (GLS), and a red clay subsoil (RC) and represented different soil textures and organic matter contents. Biocontrol isolates (CS-1, CS-20, or nontreated control) were applied at seeding (final concentration at $10^{4} \mathrm{CFU} / \mathrm{g}$ of soil). All seedlings were transplanted into pathogen-infested field soil (pathogen concentration at $10^{4} \mathrm{CFU} / \mathrm{g}$ of soil) and wilt incidence determined 6 weeks later. and did not represent significant disease development. All other cultivars tested were immune to race 1. 'Early Girl', 'Celebrity', and 'Big Beef', were also resistant to race 2 and were essentially free of disease by this race. The other five cultivars were susceptible to race 2 (although 'Rutgers' appeared to be less susceptible than the other cultivars), resulting in substantial wilt development in the pathogen control treatments (Table 4). Isolates CS-1 and CS-20 significantly reduced disease incidence on all five race 2susceptible cultivars. There were no interaction effects due to cultivar by biocontrol isolate $(P=0.91)$ indicating that the isolates were equally effective in reducing disease across all susceptible cultivars regardless of their genetic background. Overall reduction of disease relative to the pathogen controls averaged 67.2 and $65.6 \%$ with isolates CS-1 and CS-20, respectively. All cultivars tested were susceptible to race 3 with pathogen control treatments producing disease incidences of 67 to $90 \%$ in all cultivars (Table 4). Biocontrol isolates CS-1 and CS-20 were once again effective in significantly reducing disease incidence compared to the pathogen controls in all cultivars with disease incidences ranging from 0 to $35 \%$. As with race 2 , there were also no interaction effects due to cultivar by biocontrol isolate $(P=0.69)$ indicating that both isolates were equally effective in reducing disease across all cultivars. Overall reduction of disease incidence averaged 69.3 and $80.3 \%$ for isolates CS-1 and CS-20, respectively.

\section{DISCUSSION}

Inconsistencies in biocontrol under varying environmental conditions has been a common limitation of many biocontrol agents. Ideally, for practical implementation, a biocontrol agent should be effective under all circumstances where the target pathogen is capable of causing disease. One potential advantage of using biocontrol agents that are nonpathogenic strains of the same or closely related species as the pathogen is that these biocontrol agents should have similar environmental requirements. Such biocontrol agents would be most active under the same conditions that the pathogen is most active, whereas under conditions where the biocontrol agent is not active the pathogen would also not be active. Although this may be true regarding simple growth and survival requirements, in reality, there are many aspects of the

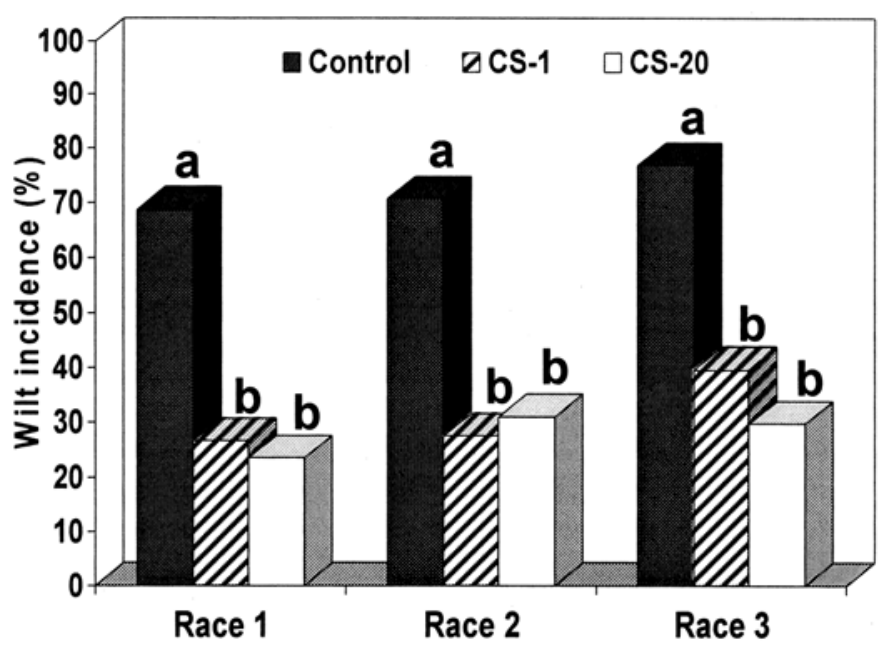

Fig. 5. Development of Fusarium wilt in tomato seedlings as affected by pathogenic race of Fusarium oxysporum $\mathrm{f}$. sp. lycopersici and treatment with biocontrol isolates. Bars topped by the same letter within each race designation are not significantly different according to Fisher's protected least significant difference test at $P=0.05$. Data represent combined results of two experiments. Biocontrol isolates (CS-1, CS-20, or nontreated control) were applied at seeding (final concentration at $10^{4} \mathrm{CFU} / \mathrm{g}$ of soil). All seedlings were transplanted into pathogen-infested field soil (pathogen concentration at $10^{4} \mathrm{CFU} / \mathrm{g}$ of soil) and wilt incidence determined 6 weeks later. 
biocontrol interaction that may be affected quite differently by environmental factors than the pathogen and subsequent disease development. Thus, efficacy of biocontrol rather than biocontrol agent populations or survival must be thoroughly evaluated under these different environmental conditions. In addition, it is important to determine not only under what conditions biocontrol is successful, but also under what conditions biocontrol is not effective.

In this study, biocontrol isolates of $F$. oxysporum (CS-20) and $F$. solani (CS-1) were observed to effectively control Fusarium wilt of tomato in different temperature regimes representing cool to hot conditions, in a number of soil types representing different textures and organic matter contents, against several different pathogen isolates and all known pathogenic races, and on several different tomato cultivars representing varying resistance characteristics to Fusarium wilt pathogens.

Temperature effects on $F$. oxysporum and wilt disease are well known. F. oxysporum grows well from 10 to $35^{\circ} \mathrm{C}$, with severe inhibition above or below these temperatures $(11,28,29)$. Fusarium wilt diseases are widely known as warm temperature diseases $(11,32)$. Optimum temperature for both the pathogen and disease development is 27 to $28^{\circ} \mathrm{C}(28,29,32)$. This was corroborated in our studies, where disease was most severe in the $27^{\circ} \mathrm{C}$ growth chamber treatment and moderate disease incidence was still apparent at $32^{\circ} \mathrm{C}$, whereas little disease developed at $22^{\circ} \mathrm{C}$. In general, biocontrol by CS-1, CS-20, and CS-24 was active throughout the entire temperature range where the disease was active significantly reducing disease incidence under all temperature regimes. CS-20, in particular, was very effective at all temperatures tested. However, under optimal conditions for disease development $\left(27^{\circ} \mathrm{C}\right.$ growth chamber), disease control by isolates CS-1 and CS-24 was less effective indicating a breakdown in biocontrol or an inability to maintain efficacy under conditions of very high disease pressure.

F. oxysporum occurs, survives, and grows in soils of all types, but sandy soils provide conditions that are most favorable for growth and development $(5,28)$. Fusarium wilt tends to be most severe in sandy soils and generally less of a problem in heavier clay soils $(5,24)$. Natural suppression of Fusarium wilt disease is known to occur in many soils $(2,24)$. This suppression is generally primarily biological in nature, but is also generally associated with particular physical-chemical characteristics such as relatively high $\mathrm{pH}$, clay, and organic matter content, all of which serve to support a large, diverse population of generally antagonistic bacteria and actinomycetes $(1,2)$. In this study, there was some variability among the soils in the development of Fusarium wilt disease with a lower level of wilt disease observed in the HSL soil (and to a lesser degree, the RC soil) indicating some natural suppressiveness to Fusarium wilt. The HSL soil has a low $\mathrm{pH}$, but also has higher organic matter content and lower sand and higher silt-clay components than the other two loamy soils tested. The RC soil is almost completely silt and clay with no organic matter. In previous work, these soils were also shown to have some degree of suppressiveness to Fusarium wilt (11). Despite these differences in characteristics and conduciveness to wilt disease, isolate CS-20 effectively reduced disease in all four soils, and CS-1 was effective in all but the clay soil.

Efficacy of biocontrol by either isolate was not affected by different pathogen isolates or race indicating that neither genetic differences among different pathogen isolates nor among different pathogenic races had much effect on the biocontrol interaction and disease control capabilities of these isolates. This is important to establish that the biocontrol interaction or mechanism of action is not restricted to a single race or select group of pathogens, but has applicability against all known pathogen types.

In addition, there was no effect due to tomato cultivar on the efficacy of either biocontrol isolate in reducing disease. Thus, not only was variation in pathogen genotype not a major factor in disease control, but host genotype, as represented by tomato cultivars with different inherent genetic resistance to Fusarium wilt, also had no significant effect on biocontrol by these isolates. Because of the their variability in response to Fusarium wilt pathogens, these eight cultivars would be expected to display differences in their defense responses or resistance mechanisms when exposed to the wilt pathogen. They also might be expected to differ in relation to their relative ability or capabilities regarding induced resistance responses. Both CS-1 and CS-20 have previously demonstrated evidence of induced resistance as a mechanism of action of biocontrol (21). However, since there was no differential effect of tomato cultivars on biocontrol by these isolates, it would appear that the effective host biocontrol response is not dependent on any specific defense mechanisms or responses found only in certain resistant cultivars. Comparable disease control was observed in all cultivars, whether completely susceptible to wilt, partially (multigenic) resistant, or completely resistant to one or more pathogenic races indicating that biocontrol by CS-1 and CS-20 can be effective regardless of the tomato cultivar used. This is in contrast to some research done on biological control of Fusarium wilt of chickpea using $F$. oxysporum and other biocontrol organisms, where it was shown that different chickpea cultivars could significantly affect the extent and consistency of biological disease suppression $(15,16)$.

Both CS-1 and CS-20 were capable of significantly reducing disease under varying environmental conditions including a variety

TABLE 4. Incidence of Fusarium wilt (\%) caused by race 2 and race 3 isolates of Fusarium oxysporum f. sp. lycopersici on eight tomato cultivars with varying disease resistance and as affected by biocontrol treatments with antagonistic Fusarium spp. (CS-20 and CS-1)

\begin{tabular}{|c|c|c|c|c|c|c|c|}
\hline \multirow[b]{2}{*}{ Tomato cultivar } & \multirow[b]{2}{*}{ Resistance $^{w}$} & \multicolumn{3}{|c|}{ Race $2^{\mathrm{x}}$} & \multicolumn{3}{|c|}{ Race $3^{x}$} \\
\hline & & CS-20 & CS-1 & Control & CS-20 & CS-1 & Control \\
\hline Bonny Best & 0 & 31.8 & 26.6 & 71.4 & 20.0 & 28.2 & 90.0 \\
\hline Marglobe & $1(\mathrm{p})$ & 20.0 & 13.2 & 63.4 & 17.4 & 35.0 & 76.8 \\
\hline Better Boy & 1 & 21.6 & 30.0 & 60.0 & 16.6 & 35.0 & 80.0 \\
\hline Miracle Sweet & 1 & 40.6 & 36.8 & 93.4 & 21.6 & 15.0 & 80.2 \\
\hline Early Girl & $1-2$ & $\mathrm{R}^{\mathrm{y}}$ & $\mathrm{R}$ & $\mathrm{R}$ & 15.0 & 42.0 & 81.6 \\
\hline
\end{tabular}

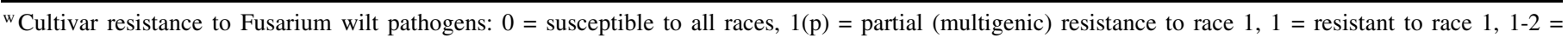
resistant to races 1 and 2 .

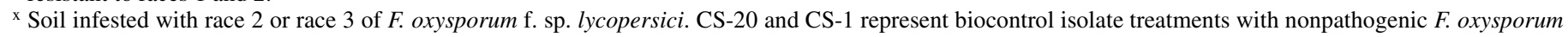
and F. solani, respectively. Control represents pathogen-infested control treatment.

y $\mathrm{R}=$ resistant to race 2 , disease incidence was $<5 \%$ for all treatments.

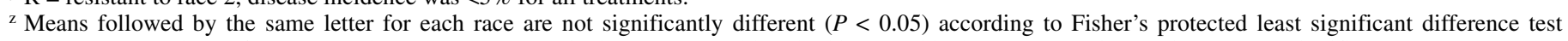
(LSD $=12.9$ and 13.1 for race 2 and race 3 tests, respectively). Tomato cultivar by biocontrol isolate treatment interaction was not significant. 
of temperature regimes, soil types, pathogen races, and tomato cultivars. There were several differences in biocontrol efficacy between the two isolates, however. Under most conditions, CS-1 appears to be an effective biocontrol agent, but as in previous research (21), biocontrol by isolate CS-1 appears to break down somewhat (or cannot quite match the rate of disease development) under extreme conditions that are either optimal for the pathogen or in some way inhibitory to the biocontrol agent. In a previous study, biocontrol by isolate CS-1 was not effective at very high pathogen inoculum levels ( $>10^{4} \mathrm{CFU} / \mathrm{g}$ of soil) (19). In this study, biocontrol by CS-1 was also less effective at the optimal temperature for disease development and under very high disease pressure, as well as in the heavy clay soil. In contrast, isolate CS-20 has continued to be our most effective isolate in controlling Fusarium wilt disease, demonstrating impressive biocontrol efficacy under virtually all conditions tested and showing strong potential as a biocontrol agent. In the current study as well as in previous research, isolate CS-20 has been effective under conditions where all other isolates have failed including at very high pathogen populations ( $10^{5} \mathrm{CFU} / \mathrm{g}$ of soil) (21) and under all environmental conditions tested. In addition, results from preliminary field trials with CS-20 have continued to look promising with significant disease reductions observed in multi-year tests on both tomato and muskmelon $(22,23)$. Currently, we are continuing to work to better understand the nature and development of biological control by CS-20 and other biocontrol agents, as well as to develop and improve the level and effectiveness of control by these isolates with the hope of developing a viable system of biological control of Fusarium wilt diseases.

\section{LITERATURE CITED}

1. Alabouvette, C., and Couteaudier, Y. 1992. Biological control of Fusarium wilts with nonpathogenic Fusaria. Pages 415-426 in: Biological Control of Plant Diseases. E. C. Tjamos, G. C. Papavizas, and R. J. Cook, eds. Plenum Press, New York.

2. Alabouvette, C., Lemanceau, P., and Steinberg, C. 1993. Recent advances in the biological control of Fusarium wilts. Pestic. Sci. 37:365373.

3. Alabouvette, C., Schippers, B., Lemanceau, P., and Bakker, P. A. H. M. 1998. Biological control of Fusarium wilts: Toward development of commercial products. Pages 15-36 in: Plant-Microbe Interactions and Biological Control. G. J. Boland and L. D. Kuykendall, eds. Marcel Dekker, New York.

4. Alexander, L. J., and Tucker, C. M. 1945. Physiological specialization in the tomato wilt fungus Fusarium oxysporum f. sp. lycopersici. J. Agric. Res. 70:303-313.

5. Amir, H., and Alabouvette, C. 1993. Involvement of soil abiotic factors in the mechanisms of soil suppressiveness to Fusarium wilts. Soil Biol. Biochem. 25:157-164.

6. Chellemi, D. O., and Dankers, H. A. 1992. First report of Fusarium oxysporum f. sp. lycopersici race 3 on tomato in northwest Florida and Georgia. Plant Dis. 76:861.

7. Cook, R. J. 1993. Making greater use of introduced microorganisms for biological control of plant pathogens. Annu. Rev. Phytopathol. 31:53-80.

8. Datnoff, L. E., Nemec, S., and Pernezny, K. 1995. Biological control of Fusarium crown and root rot of tomato in Florida using Trichoderma harzianum and Glomus intraradices. Biol. Control 5:427-431.

9. Davis, R., Kimble, K. A., and Farrar, J. J. 1988. A third race of Fusarium oxysporum f. sp. lycopersici identified in California. Plant Dis. 72:453.

10. Deacon, J. W. 1991. Significance of ecology in the development of biocontrol agents against soil-borne pathogens. Biocontrol Sci. Technol. 1:5-20.
11. Fravel, D. R., Stosz, S. K., and Larkin, R. P. 1996. Effect of temperature, soiltype, and matric potential on proliferation and survival of Fusarium oxysporum f. sp. erythroxyli from Erythroxylum coca. Phytopathology 86:236-240.

12. Grattidge, R., and O'Brien, R. G. 1982. Occurrence of a third race of Fusarium wilt of tomato in Queensland. Plant Dis. 66:165-166.

13. Handelsman, J., and Stabb, K. 1996. Biocontrol of soilborne plant pathogens. Plant Cell 8:1855-1869.

14. Hebbar, K. P., Lewis, J. A., Poch, S. M., and Lumsden, R. D. 1996. Agricultural by-products as substrates for growth, conidiation, and chlamydospore formation by a potential mycoherbicide, Fusarium oxysporum strain EN4. Biocontrol Sci. Technol. 6:263-275.

15. Hervás, A., Landa, B., Datnoff, L. E., and Jiménez-Díaz, R. M. 1998. Effects of commercial and indigenous microorganisms on Fusarium wilt development in chickpea. Biol. Control 13:166-176.

16. Hervás, A., Landa, B., and Jiménez-Díaz, R. M. 1997. Influence of chickpea genotype and Bacillus sp. on protection from Fusarium wilt by seed treatment with nonpathogenic Fusarium oxysporum. Eur. J. Plant Pathol. 103:631-642.

17. Jones, J. B., Jones, J. P., Stall, R. E., and Zitter, T. A., eds. 1991. Compendium of Tomato Diseases. The American Phytopathological Society, St. Paul, MN.

18. Komada, H. 1975. Development of a selective medium for quantitative isolation of Fusarium oxysporum from natural soil. Rev. Plant Prot. Res. $8: 115-125$.

19. Larkin, R. P., and Fravel, D. R. 1997. Efficacy of biological control of Fusarium wilt of tomato under varying environmental conditions. Phytopathology 87:S56.

20. Larkin, R. P., and Fravel, D. R. 1998. Efficacy of various fungal and bacterial biocontrol organisms for control of Fusarium wilt of tomato. Plant Dis. 82:1022-1028.

21. Larkin, R. P., and Fravel, D. R. 1999. Mechanisms of action and doseresponse relationships governing biological control of Fusarium wilt by nonpathogenic Fusarium spp. Phytopathology 89:1152-1161.

22. Larkin, R. P., and Fravel, D. R. 1999. Field efficacy of selected nonpathogenic Fusarium spp. and other biocontrol agents for the control of Fusarium wilt of tomato. Biol. Cultural Tests 14:116.

23. Larkin, R. P., Fravel, D. R., and Everts, K. L. 1999. Field efficacy of selected nonpathogenic Fusarium spp. and other biocontrol agents for the control of Fusarium wilt of muskmelon. Biol. Cultural Tests 14:160.

24. Larkin, R. P., Hopkins, D. L., and Martin, F. N. 1993. Ecology of Fusarium oxysporum f. sp. niveum in soils suppressive and conducive to Fusarium wilt of watermelon. Phytopathology 83:1105-1116.

25. Larkin, R. P., Hopkins, D. L., and Martin, F. N. 1996. Suppression of Fusarium wilt of watermelon by nonpathogenic Fusarium oxysporum and other microorganisms recovered from a disease-suppressive soil. Phytopathology 86:812-819.

26. Larkin, R. P., Roberts, D. P., and Gracia-Garza, J. A. 1998. Biological control of fungal diseases. Pages 149-191 in: Fungicidal Activity: Chemical and Biological Approaches to Plant Protection. D. Hutson and J. Miyamoto, eds. John Wiley \& Sons, New York.

27. Marlatt, M. L., Correll, J. C., and Kaufmann, P. 1996. Two genetically distinct populations of Fusarium oxysporum f. sp. lycopersici race 3 in the United States. Plant Dis. 80:1336-1342.

28. Nelson, P. 1981. Life cycle and epidemiology of Fusarium oxysporum. Pages 51-80 in: Fungal Wilt Diseases of Plants. M. E. Mace, A. A. Bell, and C. H. Beckman, eds. Academic Press, New York.

29. Nelson, P., Burgess, L. W., and Summerall, B. A. 1990. Some morphological and physiological characters of Fusarium species in sections Liseola and Elegans and similar species. Mycologia 82:99-106.

30. Paulitz, T. C., Park, C. S., and Baker, R. 1987. Biological control of Fusarium wilt of cucumber with nonpathogenic isolates of Fusarium oxysporum. Can. J. Microbiol. 33:349-353.

31. Volin, R. B., and Jones, J. P. 1982. A new race of Fusarium wilt of tomato in Florida and sources of resistance. Proc. Fla. State Hortic. Soc. 95:268-270.

32. Walker, J. C. 1971. Fusarium Wilt of Tomato. Monogr. 6. The American Phytopathological Society, St. Paul, MN. 